\title{
OBP100 binds remarkably degenerate octamer motifs through specific interactions with flanking sequences
}

\author{
Thomas Baumruker, Richard Sturm, and Winship Herr \\ Cold Spring Harbor Laboratory, Cold Spring Harbor, New York 11724 USA
}

\begin{abstract}
We have used the 100-kD HeLa cell octamer-binding protein OBP100 as a model to study flexible DNA sequence recognition by promoter-binding proteins. OBP100 binds to the conserved octamer motif ATGCAAAT found in numerous promoters and additionally to two degenerate octamer motifs (sites I and II) within the SV40 enhancer region. We show here that OBP100 binds the herpes simplex virus immediate early promoter TAATGARAT ( $R=$ purine) motif itself, extending the flexibility of OBP100 sequence recognition to sequences that bear very little resemblance (four matches over a 14-bp region). Nevertheless, a progression of OBP100binding sites can be established that links the sequences of these two apparently unrelated binding sites by incremental steps. Mutational and chemical modification interference analyses of a degenerate octamer binding site (SV40 site II) show that specific sequences, which are not normally conserved but flank the degenerate octamer motif, can compensate for the degeneracy in the octamer core sequence. Thus, different regions of the binding site sequence (core or flanking) can diverge separately but not independently of one another. These results suggest that flexible DNA sequence recognition arises because there are few obligatory contact sites for OBP100 binding, but, rather, specific binding reflects the sum of many independent interactions.
\end{abstract}

[Key Words: SV40 enhancer; herpes simplex virus; TAATGARAT motif; transcription; replication]

Received August 3, 1988; revised version accepted September 22, 1988.

Transcriptional regulation is largely mediated by the interaction of DNA-binding proteins with specific promoter elements. In eukaryotes, this process is not only complicated by the relatively large number of cis-acting elements and protein factors but also by their frequent overlapping organization and combinatorial usage /see Ondek et al. 1988). Important cis-acting elements commonly have been identified as either conserved sequence motifs (e.g., CCAAT box; Benoist et al. 1980; Efstratiadis et al. 1980) or as conserved transcription-factorbinding sites (e.g., Spl; Dynan and Tjian 1983). The existence of conserved sequence motifs and transcriptionfactor-binding sites has favored a model in which gene expression is regulated by relatively strict sequence recognition by DNA-binding proteins. Recent studies, however, have complicated the picture because some promoter-binding proteins can recognize very different sequences (Johnson et al. 1987; Pfeifer et al. 1987; Sturm et al. 1987; Costa et al. 1988; Michael et al. 1988).

Two well-characterized but apparently unrelated consensus sequences are the octamer motif ATGCAAAT, initially described in immunoglobulin gene upstream promoter and enhancer regions (Falkner and Zachau 1984; Parslow et al. 1984), and the TAATGARAT $(\mathrm{R}=$ purine) motif in herpes simplex virus (HSV) immediate early gene promoters (Mackem and Roizman $1982 b$ ). The octamer motif [also referred to as the de- camer motif ATGCAAATNA (Falkner and Zachau 1984; Falkner et al. 1986)] was characterized originally as part of a well-conserved 13-bp sequence of histone H2B promoters (Harvey et al. 1982) but has been found since in a large number of different promoters. The octamer motif has been shown to interact with both ubiquitous and lymphoid-specific cellular proteins (Landolfi et al. 1986; Singh et al. 1986; Staudt et al. 1986; Rosales et al. 1987; Scheidereit et al. 1987) and is implicated in S-phase regulation of $\mathrm{H} 2 \mathrm{~B}$ genes (LaBella et al. 1988), adenovirus DNA replication (Pruijn et al. 1986; Rosenfeld et al. 1987), regulation of small nuclear RNA transcription (Ares et al. 1985; Mattaj et al. 1985), and celltype-specific regulation of both immunoglobulin genes (Gerster et al. 1987; Wirth et al. 1987) and the SV40 enhancer (Davidson et al. 1986). Unlike the appearance of octamer elements in many different regulatory regions, the TAATGARAT sequence has only been implicated in transcriptional activation of HSV early genes by the viral gene product VP16 (or Vmw65) (Campbell et al. 1984; Kristie and Roizman 1984; Preston et al. 1984). The VP16 gene product does not bind to DNA directly (Marsden et al. 1987), but one or more cellular factors present in uninfected cells have been shown to interact specifically with the TAATGARAT element, suggesting that these may be cellular vehicles for VP16 transactivation through the TAATGARAT element /Kristie and 
Roizman 1987; McKnight et al. 1987; O'Hare and Goding 1988; Preston et al. 1988; Triezenberg et al. 1988b).

Recently, we have reported the purification from HeLa cells of a $100-\mathrm{kD}$ octamer-binding protein $(\mathrm{OBP})$, called OBP100, and described its interaction with the SV40 and immunoglobulin heavy-chain ( $\mathrm{IgH})$ gene enhancer regions (Sturm et al. 1987). This protein probably represents the ubiquitous octamer-binding factor, first called NF-Al (Staudt et al. 1986) and NF III (Pruijn et al. 1986). The IgH enhancer contains a single octamer motif, and this motif is the only IgH enhancer-binding site for OBP100. In contrast, the SV40 enhancer region lacks a perfect octamer sequence but, instead, contains the closely related sequence ATGCAAAG (Falkner and Zachau 1984). OBP100 binds to this octamer-related motif, referred to here as site I, and also binds a flanking site (site II) that was not noted by sequence comparison. Site II was shown by chemical modification interference to extend over a 13-bp sequence that contains two overlapping octamer-related sequences with six (ATGCATCT) or five (ATCTCAAT) matches (the matches are underlined) to the octamer consensus sequence. These results suggested that OBP100 can interact with degenerate octamer motifs, but that flanking sequences are important for these interactions. However, the significance of these flanking sequences was not known.

To understand the mechanism of degenerate sequence interaction, we have used mutagenesis and chemical modification interference in combination with gel retardation to examine the sequence requirements for OBP100 binding to the two SV40 octamer-related sites. Also, we have extended the repertoire of OBP100binding sites. Although the OBP100-binding site II is a degenerate octamer motif, it shares considerable sequence similarity to the TAATGARAT motif (seven/ nine match). We show that OBP100 can bind to a TAATGARAT motif that matches the SV40 site I at only 4 out of 14 positions. Together, the results reported here indicate that normally nonconserved sequences flanking an octamer motif can stabilize the interaction of a degenerate octamer core to OBP100, thereby greatly extending the flexibility of sequence recognition by OBP100.

\section{Results}

\section{Base-specific interaction of OBP100 with different octamer elements}

In our previous studies, the base-specific interaction of OBP100 with the two SV40 enhancer octamer-related sequences was deduced by chemical modification interference, in combination with a gel retardation assay (Sturm et al. 1987). In addition to dimethylsulfate (DMS), we used diethylpyrocarbonate (DEPC) to modify the DNA. DEPC modification proved superior to DMS for characterization of the two SV40-binding sites because these sites are AT rich and DEPC reacts three- to fivefold more strongly with adenosine residues than with guanosine residues. We therefore extended the DEPC interference analysis of OBP100 to other wellcharacterized octamer sites.

Figure 1 characterizes the interaction of OBP100 with four different octamer motifs: three perfect octamer motifs from the murine IgH enhancer, the human U2 small nuclear RNA (snRNA) promoter, and the chicken histone $\mathrm{H} 2 \mathrm{~B}$ promoter and one imperfect octamer (6-bp match; ATGATAAT) within the adenovirus 2 (Ad2) inverted terminal repeat (ITR). Figure 1A shows that OBP100, which has been purified extensively by DNA affinity and SDS-polyacrylamide gel electrophoresis from a heparin-agarose fraction (Sturm et al. 1987), binds to each of the four octamer sequences (lanes 1-4) in a gel retardation assay. This result is consistent with OBP100 representing the ubiquitous octamer-binding activities that have been shown to bind to these octamer elements: NF-A1 (Singh et al. 1986; Staudt et al. 1986) and NF III (Pruijn et al. 1986; Rosenfeld et al. 1987). Consistent with the ubiquitous nature of OBP100, nuclear extracts from human 293 cells, monkey kidney CV-1 cells, and mouse NS-1 and 70Z/3 lymphocytes all form the same sized gel retardation complex as the OBP100-specific complex (data not shown).

For the OBP100 DNA-binding studies described below, the source of OBP100 was the heparin-agarose fraction. This source of OBP100 has the advantage that OBP100 has not been denatured by SDS-polyacrylamide gel electrophoresis. Even though this fraction is not pure, we believe that OBP100 is the protein responsible for the binding activity being analyzed because (1) OBP100 is the only OBP we can detect in this partially purified extract (Sturm et al. 1987, and see below); (2) all of the binding activities can be competed by a single sequence (SV40 site I) that we used to purify OBP100; (3) expression of a human cDNA clone of OBP100 in Escherichia coli produces an OBP with a DNA-binding specificity that parallels the activity in the heparin-agarosepurified fraction (R. Sturm and W. Herr, unpubl.); and (4) antisera raised against the E. coli-expressed OBP100 completely inhibits octamer-specific complex formation by the heparin-agarose fraction (R. Sturm and W. Herr, unpubl.).

The results of the DEPC interference assays on both strands of the four octamer sequences are shown in Figure 1B and are summarized in Figure 1C. At each site, interfering modifications map over the 8-bp octamer sequence as well as flanking residues. Nearly all of the octamer motif modifications affect complex formation, with one notable exception: Modification of the central adenine on the top strand (ATGCAAAT) does not interfere with complex formation [see IgH, U2 snRNA, and H2B in Fig. 1, SV40 site I in Sturm et al. (1987), and Fig. 4 below]. The interference by modification of flanking residues has been noted also by DMS modification of flanking guanines (Ares et al. 1987; Pruijn et al. 1987; Rosales et al. 1987). The detrimental effect of flanking modifications within nonconserved residues suggests a role for these sequences in OBP100 binding but without strict sequence requirement. 

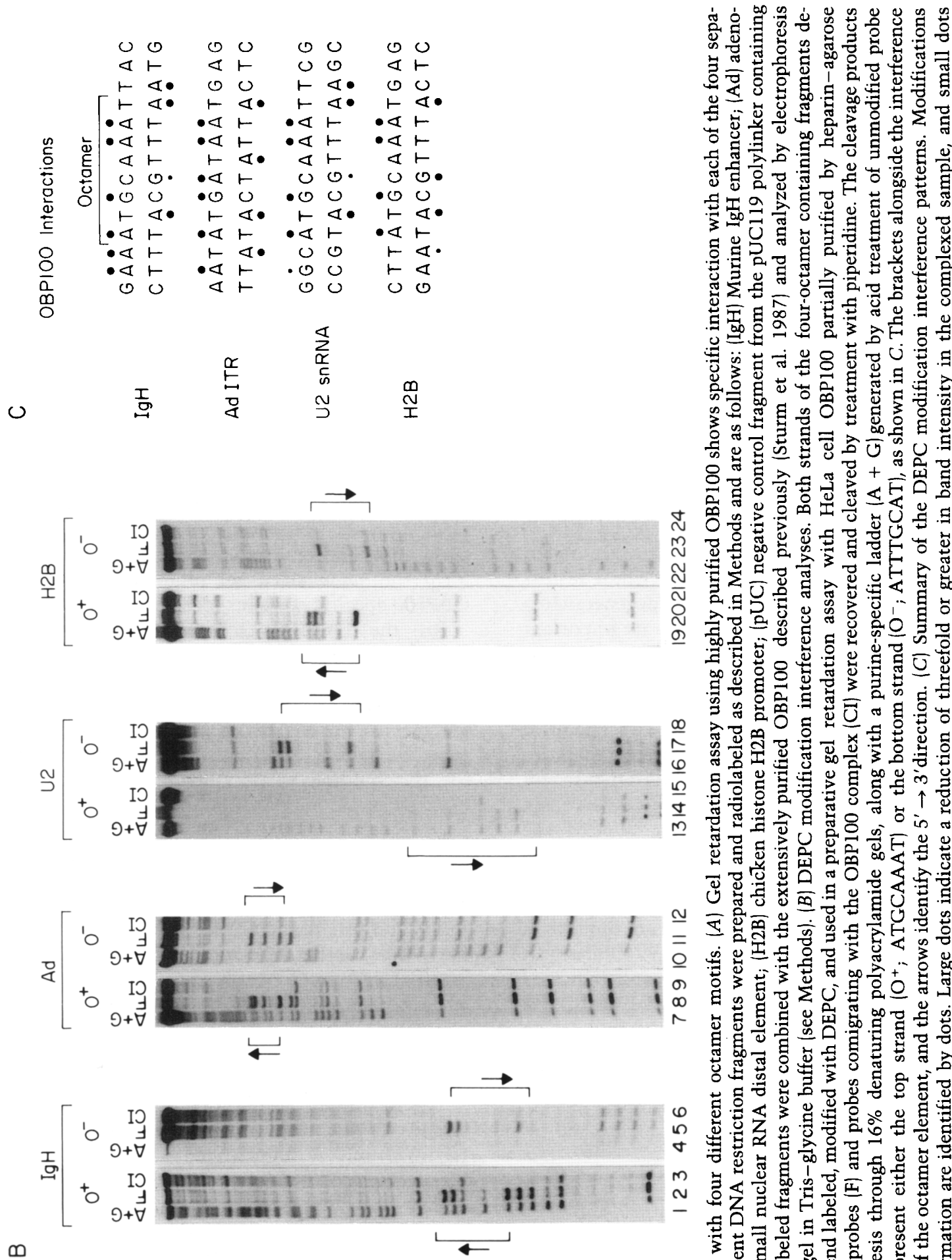

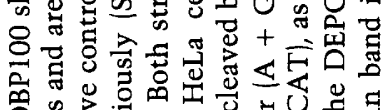

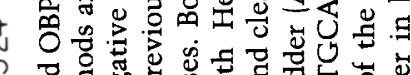

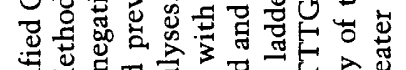

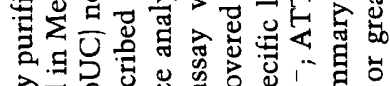

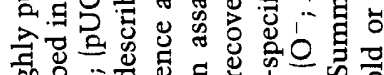

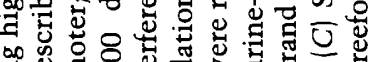

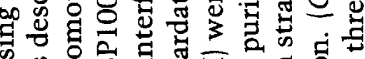

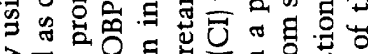

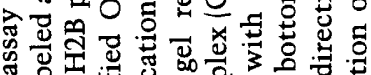

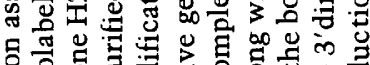

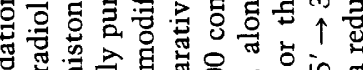

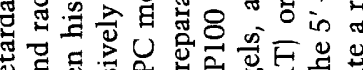

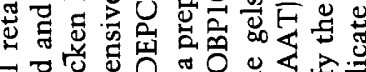

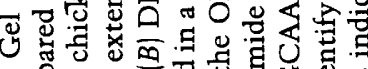

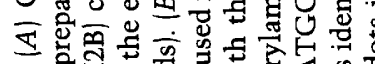

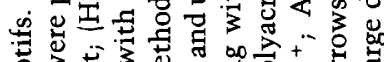

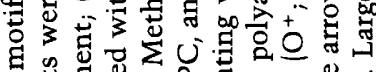

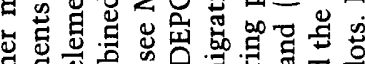

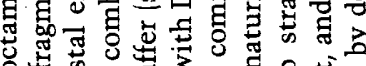

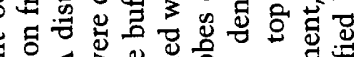

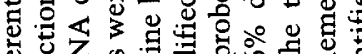

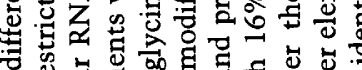

可论

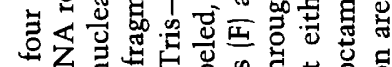

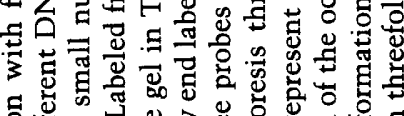

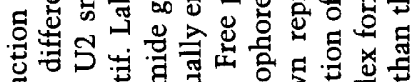

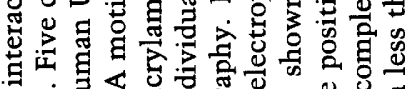

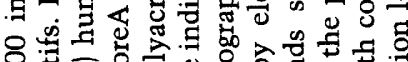

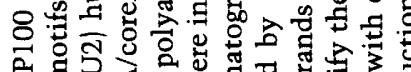

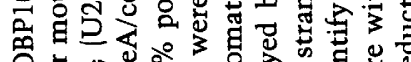

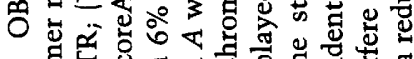

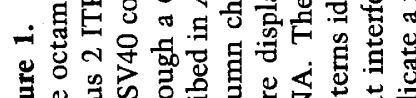

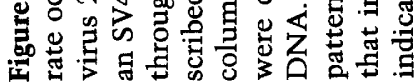


Boundaries of the SV4O OBP100-binding sites I and II

Figure $2 \mathrm{~A}$ shows a diagram of the SV40 early promoter with the sequence of the OBP100-binding site region displayed below. Over the sequence, three octamer-re- lated sequences, Octa1, Octa2, and Octa3, which lie within the OBP100-binding site region, are identified. These octamer-related sequences contain seven (Octal), six (Octa2), and five (Octa3) matches to the 8-bp octamer consensus sequence. Below the sequence, the dashed

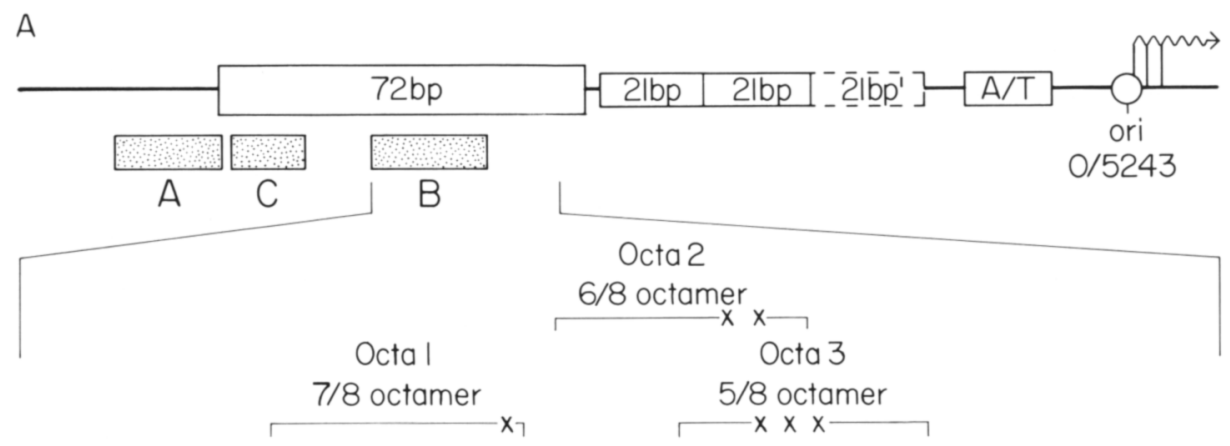

GCAGAAGTATGCAAAGCATGCATCTCAATTAGTCAGCA C GTCTTCATACGTTTCGTACGTAGAGTTAATCAGTCGT
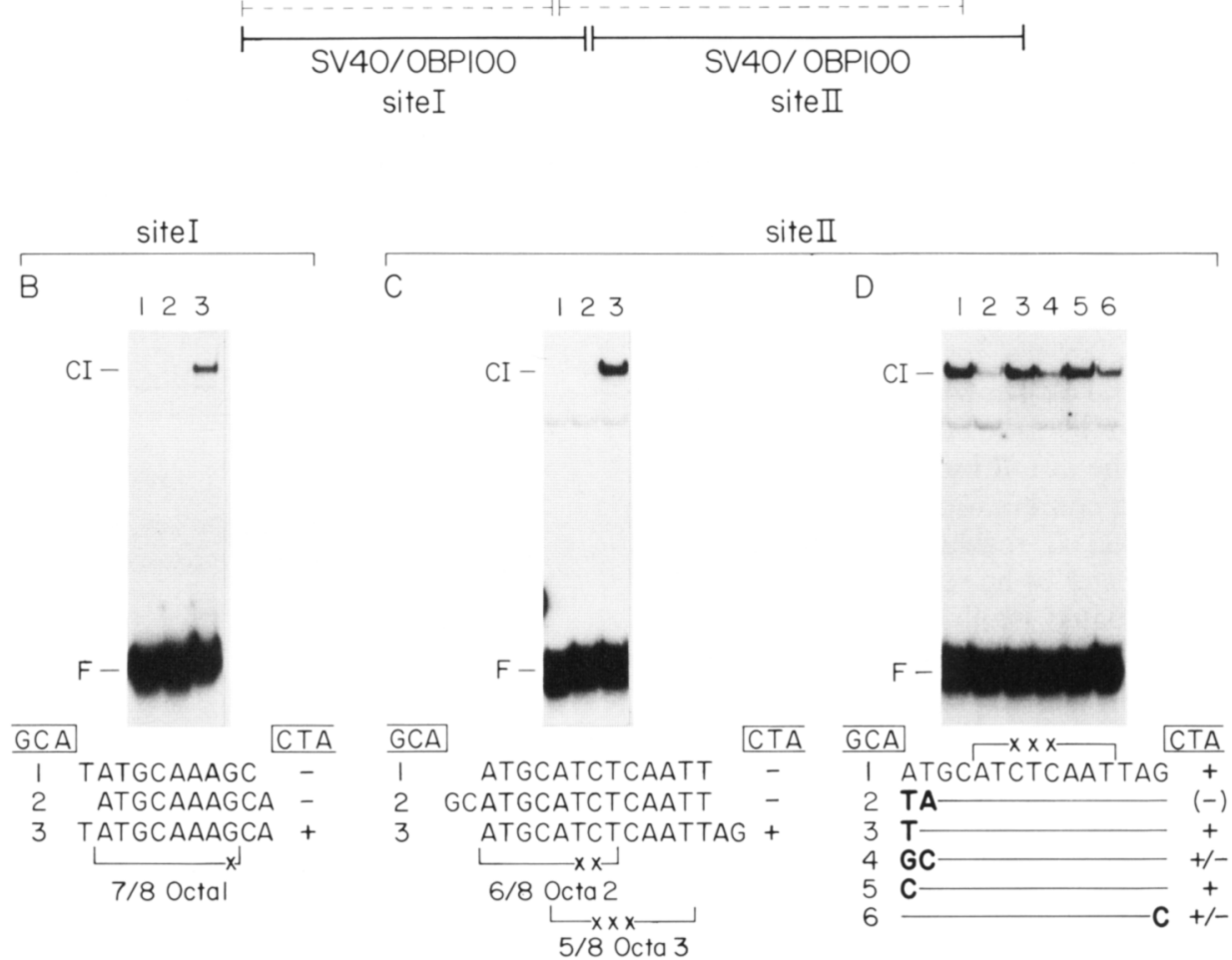

Figure 2. Definition of the two SV40 enhancer OBP100-binding sites I and II. (A) Diagram of the SV40 early promoter with one copy of the 72-bp repeat. Represented from right to left are the early transcription start sites (wavy arrows), the origin (ori) of replication, the TATA-like sequences $(\mathrm{A} / \mathrm{T})$, and the 21 -bp repeats. Below the 72 -bp repeat region is shown the position of the $\mathrm{A}, \mathrm{B}$, and $\mathrm{C}$ enhancer elements, as defined by Herr and Clarke (1986). Below the diagram is shown a part of the 72-bp sequence spanning the OBP100binding sites. Above the sequence, three octamer-related sequences (Octa1-Octa3) are bracketed with mismatches to the octamer consensus shown by Xs. Below the sequence are shown the two SV40 OBP100-binding sites as originally defined by chemical interference analysis (Sturm et al. 1987) (dashed lines) and as defined in this paper by oligonucleotides and mutagenesis (solid lines). ( $B-D$ ) Gel retardation assays of wild-type and mutant SV40 OBP100-binding sites I and II. Gel retardation assays were performed with HeLa cell nuclear extract partially purified for OBP100 by heparin-agarose column chromatography. The probes were EcoRI-HindIII-digested fragments continuously labeled on one strand (see Methods). The free (F) and complexed (CI) probes are indicated. The lane numbers in each panel correspond to the numbered sequences shown below that were used as probe, along with the flanking polylinker nucleotides shown boxed. As diagramed, the pUC119 HindIII site lies to the left. The octamer-related sequences Octa1-Octa3 are bracketed, indicating the positions that differ from the octamer consensus sequence ATGCAAAT. A qualitative measure of the relative levels of complex formation with each probe is indicated by the + and - designations to the right of each sequence. $(B)$ Site I definition; $(C)$ Site II definition; $(D)$ Effect of mutations at the boundaries of site II. Mutations are shown in boldface type, and the straight line indicates identity with the wild-type site II sequence shown above. 
line shows the limits of the two SV40 OBP100-binding sites, as defined previously by DEPC and DMS modification interference (Sturm et al. 1987). From the chemical interference studies, OBP100-binding site II spanned both octamer-related sequences Octa2 and Octa3, of which only the former was noted in our previous study (Sturm et al. 1987). To study the SV40 sites I and II separately, we used synthetic oligonucleotides to create individual binding sites within the pUC119 polylinker, and these were used in gel retardation assays (see Methods). Unexpectedly, neither of the two sites defined by chemical interference bound to $\mathrm{OBP} 100$ in a gel retardation assay (Fig. 2B,C, lanes 1).

To elucidate the boundaries of binding sites I and II, the synthetic oligonucleotide sequences were extended in either direction. Figure $2 \mathrm{~B}$ shows that shifting the entire binding site I by $1 \mathrm{bp}$, to contain the decamer-related sequence ATGCAAAGCA, does not recreate the OBP100-binding site (lane 2), but addition of the 5'flanking $\mathrm{T}$ residue to the decamer motif restores OBP100 binding (lane 3). Thus, these studies define site I as an 11-bp binding site. Site II was defined similarly, as shown in Figure 2C; extension of the sequences $5^{\prime}$ of the Octa2 sequence did not restore octamer-binding activity (lane 2), but two additional residues $3^{\prime}$ of the Octa3 motif did restore activity (lane 3 ). The exact boundaries of site II were defined more precisely by mutagenesis of the external residues of the active binding site II (Fig. 2D). These studies show that the $5^{\prime} \mathrm{A}$ residue of the Octa2 sequence is not essential for OBP100 binding to site II (Fig. 2D, lanes 3 and 5), but when the two $5^{\prime} \mathrm{A}$ and $\mathrm{T}$ residues are mutated by transitions (lane 4 ) or by transversions (lane 2), the site II binding activity is impaired. These results, in combination with the effect of mutating the 3 '-terminal $\mathrm{G}$ residue (lane 6), indicate that site II extends over the 14-bp sequence TGCATCTCAATTAG (octamer-related residues are identified by underlining), in which the degenerate Octa3 motif is centrally located. These mutagenesis studies indicate that the more closely octamer-related Octa2 sequence does not bind to OBP100 in these assays (see Fig. 2C, lane 2); this result emphasizes the difficulty in identifying protein-binding sites by sequence similarity. Furthermore, the differences between the mutagenesis results described here and our prior results with chemical modification (cf. the dashed line and solid line in Fig. 2A) show that chemical interference patterns are insufficient to define an entire binding site.

\section{Flanking residues stabilize OBP100 binding to a degenerate octamer}

The interaction with SV40 site II shows that OBP100 can bind to very degenerate octamer motifs, but because of the large size (14 bp) of this binding site, appropriate flanking residues appear to be necessary for OBP100 to bind such a degenerate octamer motif. It is unlikely, however, that specific flanking interactions are essential for binding to a perfect octamer motif because these residues are not conserved between different octamer sites.
To test this hypothesis we created three point mutations within the degenerate Octa3 sequence, creating a perfect octamer motif (ATGCATGCAAATTAG) and then compared (1) the effect of these mutations on OBP100 affinity for site II and (2) the effect of mutations and chemical modifications in sequences flanking the perfect and degenerate site-II octamer sequences.

Figure 3 shows a competition experiment in which the binding affinity of OBP100 to the wild-type SV40 site II and perfect octamer mutant has been compared to the affinity for the perfect H2B octamer and SV40 site I. In each case, the same restriction fragment, containing 14 copies of the SV40 site I $(14 \times \mathrm{B} 17$; Ondek et al. 1987), was used as competitor in 3.3-fold serial dilutions. The relative rate at which the OBP100 complex disappears is an indication of relative affinity. The re-

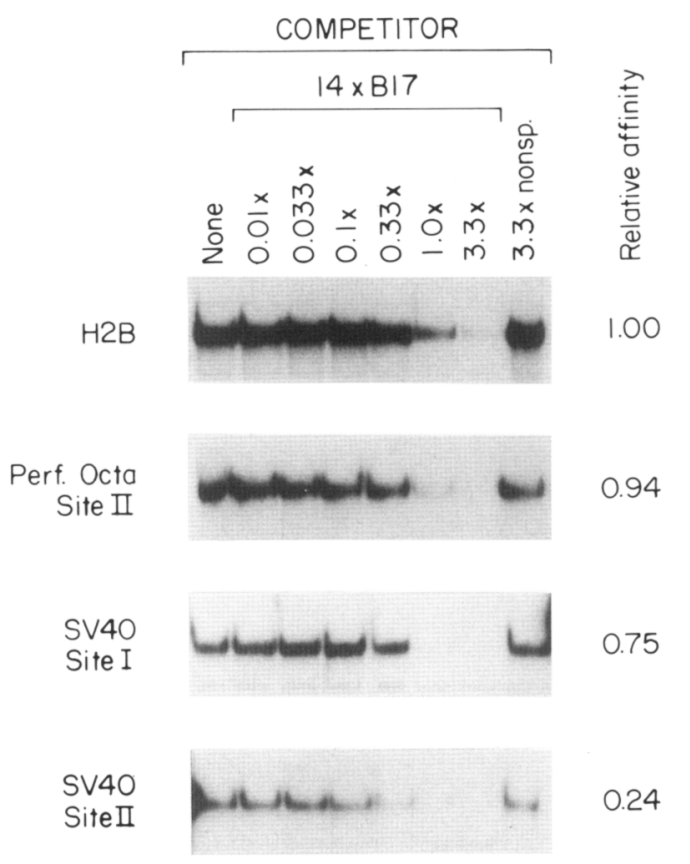

Figure 3. Gel retardation competition experiments to assay the relative affinity of two perfect $(\mathrm{H} 2 \mathrm{~B}$ and the perfect site II octamer) and two imperfect (wild-type SV40 sites I and II) octamer motifs for complex formation. The gel retardation assays were performed with continuously labeled probes and the heparin-agarose-purified $\mathrm{HeLa}$ cell nuclear extract containing OBP100. Only the retarded complexes for each series of competition are shown. The specific competitor, $14 \times \mathrm{xB} 17$ restriction fragment, or nonspecific competitor, HaeIII-digested $\lambda$ phage DNA, were mixed together before addition of the protein extract. The specific competitor was added in 3.3-fold serial dilutions starting with a 100 -fold greater number of competitor binding sites to probe binding sites $(3.3 \times)$. The nonspecific competitor was at the same concentration of competitor DNA as in the $3.3 \times$ lane with the $14 \times B 17$ fragment. The exposures differ so that the bands representing the complexes are of more equal intensity. To quantitate the disappearance of the complexes, the films were scanned with a densitometer, and the midpoint of disappearance of the complex identified. The relative concentration of competitor necessary to reach this midpoint is shown as the relative affinity with respect to the H2B probe. 
sults show that the 3-bp change that creates a perfect site II octamer sequence creates a considerably better OBP100-binding site, having nearly as high an affinity as the perfect $\mathrm{H} 2 \mathrm{~B}$ octamer site and better than site I. The high affinity of the perfect octamer in site II is partially a result of its context because not all perfect octamer for decamer) motifs bind OBP effectively. For example, in a different context, mutating the Octa2 sequence to a perfect octamer (decamer) sequence created an OBP100binding site with only the same affinity as the wild-type degenerate site II sequence (data not shown).

Figure 4 shows that interactions with flanking residues that are essential for effective binding of OBP100 to the site II degenerate octamer are not critical for binding when the site II octamer is changed into a perfect octamer. First, when the double AT $\rightarrow$ TA point mutation that affects site II interactions (Fig. 4A, lanes 1 and 2 ) is incorporated into the perfect octamer site II sequence, there is little effect on OBP100 binding /cf. lanes 3 and 4 in the shorter exposure). Second, Figure 4, B and $\mathrm{C}$, shows that DMS and DEPC modifications of residues flanking the wild-type site II Octa3 sequence that interfere with OBP100 binding have little effect on binding to the perfect octamer site II. Thus, whereas modification of either strand of the 5'-flanking TGC sequence interferes with binding to the wild-type degenerate site II, these modifications interfere little with binding to the perfect octamer sequence (see arrowheads in Fig. 4B). This difference does not appear to result from a shift in the OBP100-binding site in the perfect site II octamer sequence because the interference pattern remains the same on the $3^{\prime}$ side of the octamer sequence and does not include the flanking polylinker sequences. Although flanking modifications do not prevent binding to the perfect site II octamer, modifications within the perfect octamer sequence have a large effect on binding. Indeed, the very strong DEPC modification interference pattern on the top strand of the perfect octamer flanes 11 and 12), compared to the weaker interference pattern over the imperfect octamer (lanes 8 and 9), suggests that contacts within the octamer sequence become more critical when it is a perfect match to the consensus.

Together, these results indicate that the interaction of OBP100 with the degenerate site II octamer sequence is the result of interactions with flanking residues that are not essential for binding to a perfect octamer. The complementary view is that mutations within a binding site can relieve the requirement for specific flanking residues. We have observed this effect with other binding sites as well. For example, if the incomplete SV40 site I sequence TATGCAAAGC, which is missing the $3^{\prime}$ flanking A residue required for OBP100 to bind (cf. Fig. $2 B$, lanes 1 and 3 ), is mutated to the perfect octamer sequence TATGCAAATC, this flanking A residue is not required (data not shown). We also found that a mutation that changed the nonbinding site II sequence ATGCATCTCAATT (Fig. 2C, lane 1) to ATGCATCTCATTT (called clone 12) created a binding site in the absence of the 3 -flanking AG sequence required for binding to site II (Fig. 2C, lane 3). [Although this muta- tion destroys one of the five matches between Octa3 and the octamer consensus, it becomes more similar to the TAATGARAT motif (see below.)] Thus, changes within a binding site for OBP100 can affect the requirement for both $5^{\prime}$ - and $3^{\prime}$-flanking residues. Nevertheless, the high affinity of OBP100 for the perfect octamer sequence within site II (Fig. 3) indicates that residues flanking even a perfect octamer motif still contribute to the binding of OBP100 to DNA. In the experiments described in Figure 4, the effect of the residues flanking the perfect site II octamer probably has gone undetected because the mutations and modifications that have a large effect on wild-type site II binding are too subtle to have a large effect on binding to the perfect site II octamer.

\section{$O B P$ binds to the HSV TAATGARAT motif}

Kristie and Roizman (1987) noted a sequence similarity between the SV40 OBP100 site II sequence and, in inverse orientation, the TAATGARAT motif of HSV immediate early promoters. The degenerate Octa3 sequence is very similar to the inverse orientation of the TAATGARAT motif [ATCTCAAT (Octa3) compared to ATYTCATTA (TAATGARAT); $Y=$ pyrimidine], but the TAATGARAT motif itself is only a 4-bp match with the octamer motif (ATYTCATT). A host cell factor(s), variously called H1 (Kristie and Roizman 1987), HC3 (Preston et al. 1988), and TRF (O'Hare and Goding 1988), has been identified in uninfected HeLa cell extracts; it binds specifically to the TAATGARAT motif. Given the high degree of sequence similarity between the SV40 OBP100 site II sequence and the TAATGARAT motif, we tested the ability of OBP 100 to bind to the TAATGARAT motif, thereby possibly expanding the repertoire of highly degenerate OBP100 octamer-binding sites to a new class of regulatory elements.

To accomplish this goal, however, it was necessary to choose carefully the TAATGARAT motif for analysis because many TAATGARAT motifs contain overlapping sequences with a much higher degree of sequence similarity to the octamer motif. For example, Pruijn et al. (1986) and O'Hare and Goding (1988) have noted overlapping octamer motifs in several TAATGARAT motifs but on the same strand [e.g., the seven out of eight octamer sequence ATGCTAATGATAT in a nearly perfect TAATGARAT motif within the ICP0 (IE110K) promoter]. Therefore, to show that OBP100 can bind directly to the conserved TAATGARAT motif and not to overlapping octamer motifs, we chose to study the TAATGARAT motif located $260 \mathrm{bp}$ upstream of the transcriptional initiation site for the ICP4 (IE175K) gene. The sequence of this site is shown in Figure 5C, and whereas it is a perfect match to the TAATGARAT motif (identified by the arrow on the lower strand in Fig. 5C) and is functional for VP16 transactivation (Triezenberg et al. 1988b), it only contains at best 4-bp matches to the octamer motif. The match that corresponds to the octamer motif similarity in the SV40 Octa3 sequence is shown by the bracket above the TAATGARAT sequence in Figure 5C.

When an 87-bp SphI/NcoI restriction fragment from 
the ICP4 promoter region containing the -260 TAATGARAT motif was used in a gel retardation assay with the heparin-agarose-purified HeLa cell fraction, a single retarded complex comigrating with the OBP100 complex formed (data not shown). Figure 5A shows that formation of this complex can be inhibited by competition with unlabeled SV40 site I DNA as readily as SV40 site
II, indicating that the same factor(s) is responsible for both complexes and has a similar affinity for both sites. A DEPC modification interference assay, shown in Figure $5 \mathrm{~B}$ and summarized in Figure $5 \mathrm{C}$, shows that the interaction responsible for complex formation is indeed with the TAATGARAT motif. The interfering modifications include all but two of the residues in the TAAT-

A
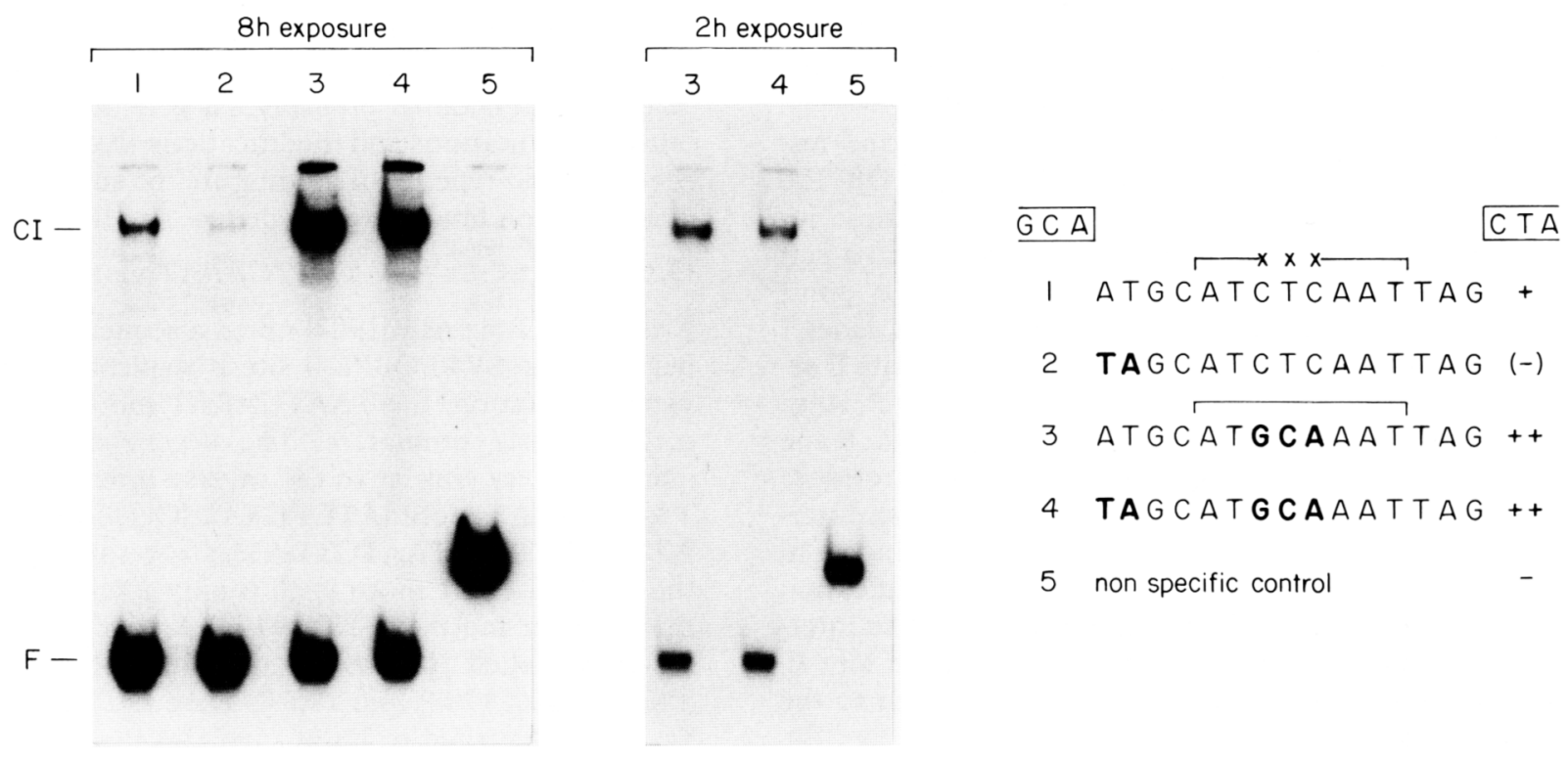

B

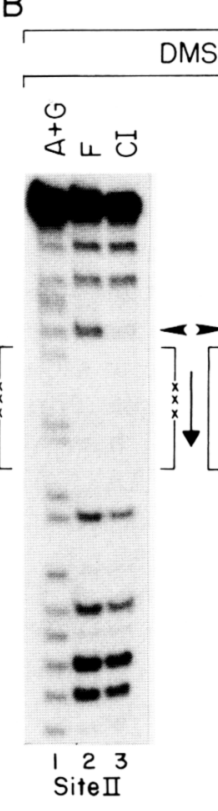

SV40

Site II

perf. Octa

SiteII

Top Strand

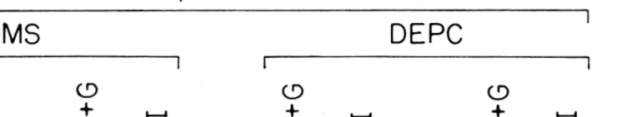
㐫山它
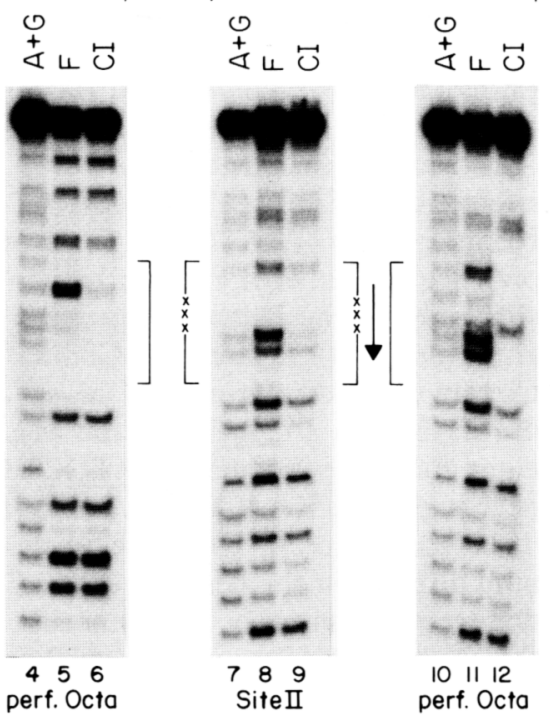<smiles>C1CCC1</smiles>
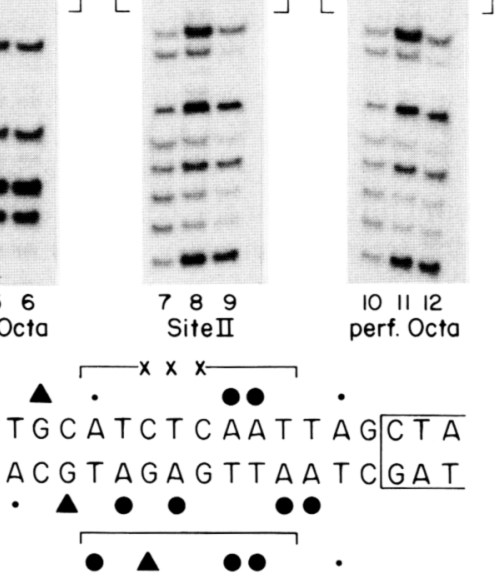

GCAATGCATCTCAATTAGCTA CGTTACGTAGAGTTAATCGAT

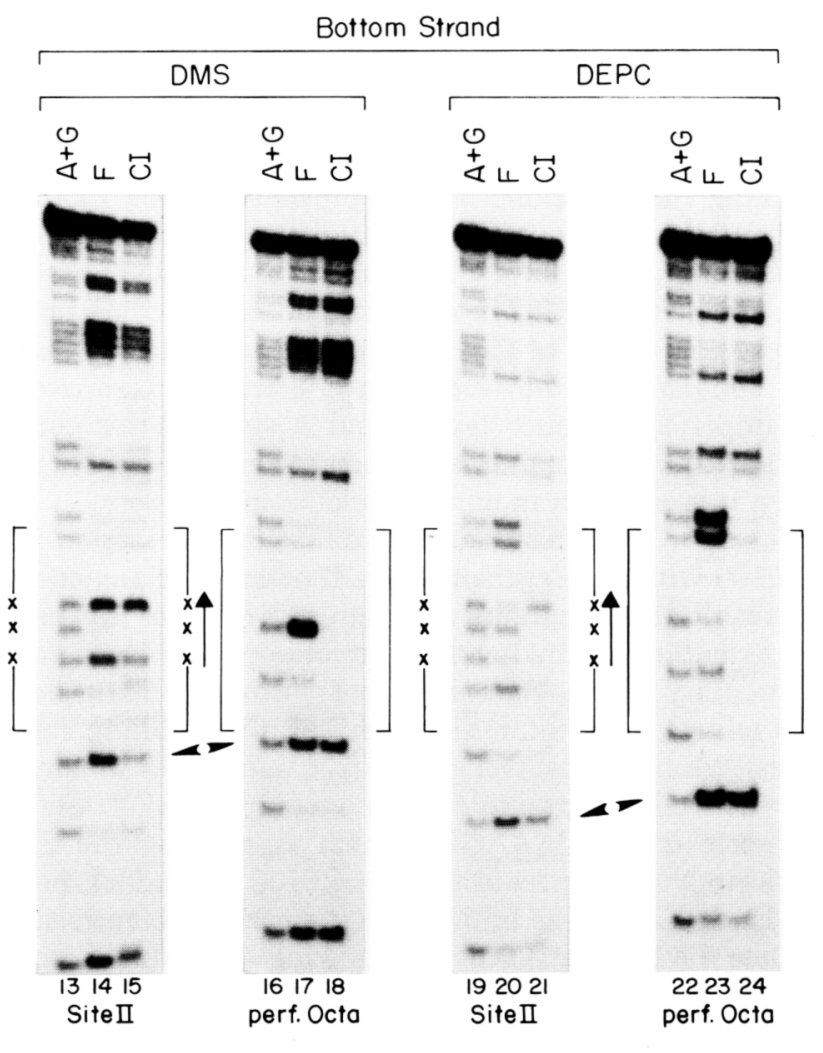

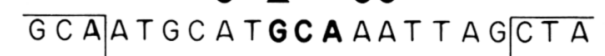

CGTTACGTACGTTTAATCGAT

Figure 4. (See facing page for legend.) 
A

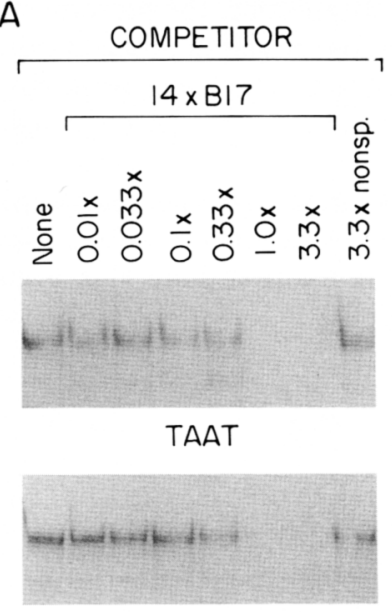

SV40 Site II

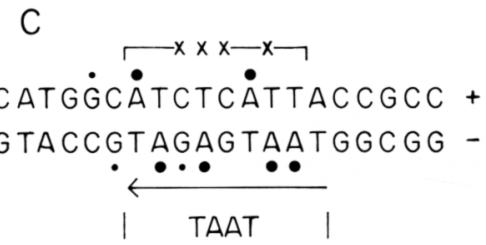

B

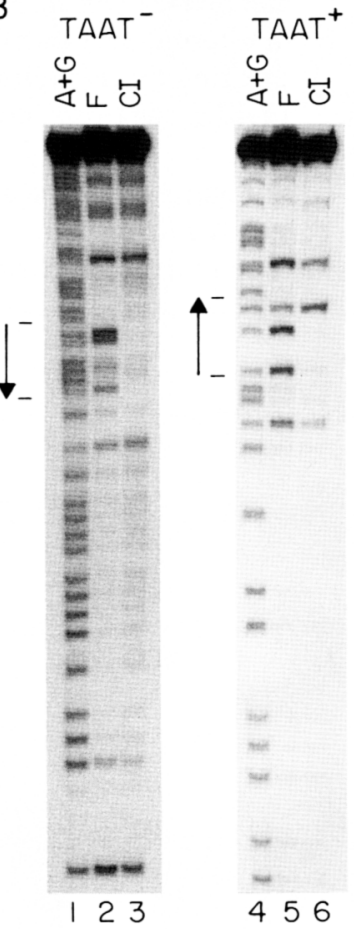

Figure 5. OBP binds to the HSV TAATGARAT motif. $(A)$ Gel retardation competition analysis. The competition experiments were performed as described in the legend to Fig. 3, using the $14 \times \mathrm{B} 17$ restriction fragment as unlabeled competitor in 3.3fold serial dilutions and continuously labeled probes of the TAATGARAT motif (top) and wild-type SV40 site II (bottom) as cloned oligonucleotides (see Methods) after excision from the pUC119 polylinker by digestion with EcoRI and HindIII. The source of OBP100 was heparin-agarose-fractionated HeLa cell nuclear extract. Only the retarded complexes are shown. The highest level of competitor represents a 100 -fold greater number of competitor binding sites to probe binding sites. The nonspecific competitor was HaeIII-digested $\lambda$ DNA in equal concentration to the highest level of $14 \times \mathrm{B} 17$ fragment. $|B|$ DEPC modification interference analysis of the TAATGARAT motif. The 87-bp NcoI-SphI restriction fragment spanning the -260 TAATGARAT motif of the ICP4 promoter was either $3^{\prime}$ $\left(\mathrm{TAAT}^{-}\right)$or $5^{\prime}\left(\mathrm{TAAT}^{+}\right)$end labeled at the $\mathrm{NcOI}$ site with the Klenow fragment of DNA polymerase or T4 polynucleotide kinase, respectively. The end-labeled DNAs were modified with DEPC, used in a preparative gel retardation with heparinagarose-purified OBP100 and cleaved with piperidine, and the resulting fragments fractionated by electrophoresis through a $16 \%$ denaturing polyacrylamide gel as described in Methods. $(A+G)$ Purine ladder; (F) free probe; (CI) retarded complex. The boundaries of the TAATGARAT motif are identified by the dashes with the arrow, indicating the $5^{\prime}$ to $3^{\prime}$ direction of the sequence. $(C)$ Summary of chemical interference experiments. Shown is the double-stranded sequence of the -248 to -267 (left to right) region of the ICP4 promoter with the TAATGARAT motif on the bottom strand (arrow and dashes) and the octamer-related sequence shown on the top strand (bracket with $\times s$ for mismatches to the octamer consensus). The + (top strand) and - (bottom strand) designation correspond to $\mathrm{TAAT}^{+}$and TAAT $^{-}$in $B \mid$. The large dots indicate adenine modifications that result in a decrease in band intensity greater than threefold in the CI samples, and the small dots indicate an interference by DEPC modification of guanosines of two- to threefold.

GARAT motif, and extend $2 \mathrm{bp}$ to the left of the motif as shown in Figure 5C. The 2-bp extension is the same as the GC dinucleotide interaction just upstream of the
Octa3 motif in SV40 site II (see Fig. 4).

Given the low degree of sequence similarity between the TAATGARAT and octamer motifs, it is difficult to

Figure 4. Changes within a core octamer motif affect the requirement for flanking sequences. (A) Gel retardation assay with continuously labeled DNA probes (see Methods and legend to Fig. 2) and partially purified OBP100 from a HeLa cell nuclear extract. The nucleotide sequence of the variable portion of each probe is shown with the designations corresponding to the lane numbers. The nonspecific control (lane 5) is a pUC119 polylinker with the coreA/coreA fragment sequence. Differences between the nucleotide sequence of the wild-type SV40 OBP100-binding site II (lane 1) and the sequence of site II with flanking mutations (lane 2) or the perfect octamer in site II with (lane 4) or without (lane 3) flanking mutations are shown in boldface type. The boxed sequences shown above represent adjacent polylinker sequences, the brackets indicate the sequences similar $(1$ and 2$)$ or identical $(3$ and 4$)$ to the octamer consensus, and the + and - designations represent a qualitative assessment of OBP-binding affinity. The shorter 2-hr exposure of lanes $3-5$ is of the same gel as the $8-\mathrm{hr}$ exposure shown. (F) Free probe, (CI) complexed probe. (B) DMS and DEPC modification interference analysis of the wild-type (site II) and perfect octamer (perf. octa) site II probes shown in $A$ (probes 1 and 3 , respectively). DNAs modified with DMS or DEPC were used in a preparative gel retardation with partially purified OBP100, and subsequently cleaved with piperidine and displayed on $16 \%$ (top strand) or $20 \%$ (bottom strand) denaturing polyacrylamide gels, as described in Methods. The top strand was displayed by $3^{\prime}$ end labeling at the pUC119 polylinker EcoRI site, and the bottom strand by $3^{\prime}$ end labeling at the HindIII site. $(A+G)$ Purine ladders for each fragment generated by acid treatment. The free $(F)$ and complexed (CI) probes are shown in pairs for each site. The brackets identify the positions of the octamer related Octa3 sequence (with Xs) or the perfect octamer, and the arrows show the relationship of the modification pattern to the sequence shown in $C$ in a left-to-right direction. The arrowheads identify modifications of residues flanking the octamer motifs that have different effects between wild-type SV40 site II and the perfect octamer site II. (C) Summary of the chemical interference patterns. The guanosine DMS ( $\mathbf{\Delta})$ and adenosine DEPC $(\bullet /$ modifications that interfere with complex formation are shown above and below the double-stranded sequence of the two binding sites. The brackets over the octamer motifs, boxed polylinker sequences, and mutations in boldface type are as described in $A$. The large triangles and circles indicate a reduction in band intensity threefold or greater in the complexed DNA probes; the small circles indicate a reduction of two- to threefold; effects less than twofold have not been included. The relative band intensities were assayed by densitometry. 
know how the octamer and TAATGARAT motifs should be aligned. We favor the alignment shown in Figure $5 \mathrm{C}$, with the degenerate octamer motif centered over the opposite strand from the TAATGARAT motif sequence because of the patterns of DEPC interference, which are very similar between this TAATGARAT motif and SV40 site II (cf. Figs. 4 and 5). It should be noted, however, that the strand containing the TAATGARAT motif itself also has a 4-bp match (ATGAGATG) to the octamer motif within the region of interferring modifications. Indeed, even the other strand of a perfect octamer motif (ATTTGCAT) has a 4-bp match to the octamer consensus sequence. The TAATGARAT interference pattern shown in Figure 5B indicates, however, that there is no obvious OBP100 interaction with the bases $1-4$ bp $5^{\prime}$ of this TAATGARAT motif /GCGG on the bottom strand), which correpond to the region of octamer similarity noted in other TAATGARAT motifs by Pruiin et al. (1986) and O'Hare and Goding (1988). Thus, OBP can bind to the TAATGARAT motif itself and not just flanking octamer motifs. In conclusion, the interaction with the TAATGARAT motif described here indicates that octamer-binding protein can exhibit remarkably flexible sequence recognition to sequences that are important regulatory elements in vivo.

Our interpretation is likely to be controversial, however, because O'Hare and Goding (1988) and Gerster and Roeder (1988) have emphasized the overlapping octamer motifs as the site of interaction by OBPs. But unlike the experiment shown in Figure 5, these studies did not analyze the actual site of OBP interaction by chemical modification interference analyses, which can identify the actual protein-binding site. It seems likely that when a TAATGARAT motif is overlapped by an octamer motif, the octamer motif will be the primary OBP100-binding site. But if the octamer motif is mutated without affecting the TAATGARAT motif las in the TAAT9 and TAAT10 mutants described by $\mathrm{O}^{\prime}$ Hare and Goding (1988)], then the OBP100-binding site is likely to shift to the TAATGARAT motif and interact in a manner analogous to the interaction with the solitary TAATGARAT motif described here. As described below, VP16 may be involved in generating just such a shift in binding site preference.

\section{OBP100 is responsible for the interaction with the TAATGARAT motif}

The SV40 site I and -260 ICP4 TAATGARAT motif share very little sequence similarity ( 4 out of $14 \mathrm{bp}$ ) but form the same gel retardation complex and compete with one another for the same factor(s) in the partially purified HeLa cell extract. To test further whether OBP100 was responsible for the interaction with the TAATGARAT motif in the heparin-agarose-purified fraction and to test whether other polypeptides might be involved in complex formation, we used a DNA affinityprecipitation technique. This technique (Franza et al. 1987) is a simple microscale assay in which biotinylated DNA probes are allowed to incubate with the extract in the presence of nonspecific competitor; the proteins that are bound specifically to the biotinylated probe are then purified by precipitation of the DNA probes with streptavidin-agarose beads and analyzed by gel electrophoresis.

Figure 6 shows a silver-stained SDS-polyacrylamide gel resulting from a DNA affinity-precipitation assay. The starting heparin-agarose fraction (lane 1) is a com-

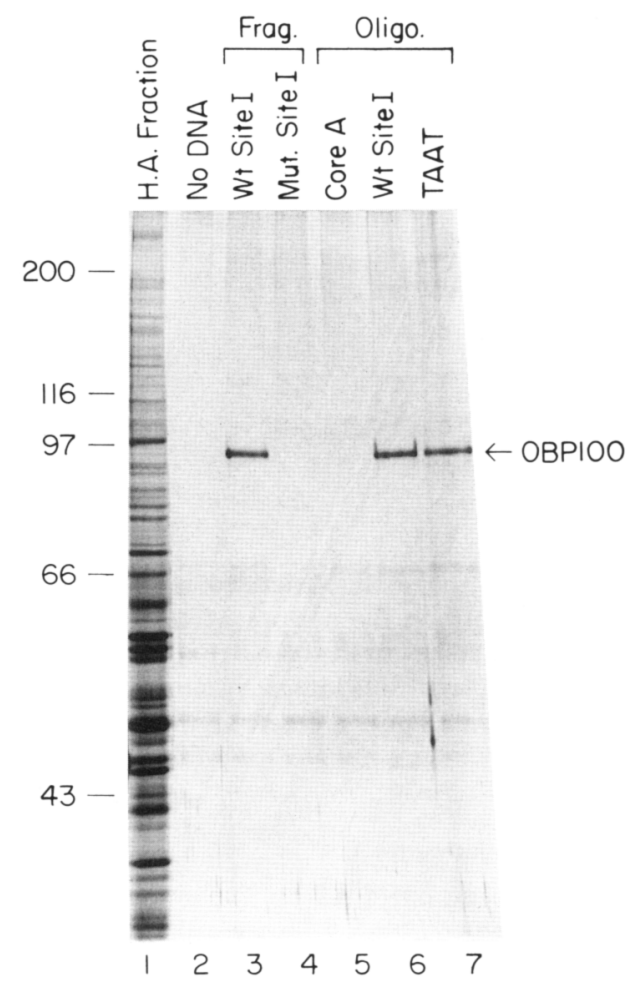

Figure 6. Microscale DNA affinity precipitation of OBP100 with the octamer-related SV40 site I and the dissimilar TAATGARAT motif. DNA affinity precipitation with biotinylated DNA fragments was performed with the heparin-agarose-fractionated HeLa nuclear extract as described in Methods. Shown is a silver-stained $8 \%$ polyacrylamide-SDS gel. The position of the molecular weight markers is shown to the left. (Lane 1) $1 / 250$ portion of the starting material used in DNA affinity precipitation shown in lanes 2-7. (Lane 2) No biotinylated DNA in the precipitation. The DNA probes used were $14 \times \mathrm{B} 17$ (lane 3) and $6 \times \mathrm{B} 17 d p m 8$ (lane 4) HindIII-PstI restriction fragments and coreA/coreA (lane 5), sphII/MsphI (wt SV40 site I; lane 6), and TAATGARAT (lane 7) ligated double-stranded synthetic oligonucleotides. The coreA/coreA oligonucleotide (Ondek et al. 1988) is a sequence unrelated to the octamer motif, and dpm 8 is a double-point mutation (AAGGAAAG) within the SV40 site I octamer motif. The position of OBP100 is marked. The slightly faster mobility of OBP100 compared to the 97.4$\mathrm{kD}$ rabbit muscle phosphorylase $\mathrm{B}$ marker, as opposed to its previous apparent molecular weight of $100 \mathrm{kD}$ (Sturm et al. 1987 ), is due to changes in polyacrylamide gel electrophoresis conditions (e.g., bis-acrylamide to acrylamide ratio in the gel). This polyacrylamide gel-specific shift in apparent molecular weight may explain some of the differences in the reported molecular weight of OBPs [e.g., the $90-\mathrm{kD}$ OTF-1 (Fletcher et al. 1987 ) and the 92-kD NFIII (O'Neill and Kelly 1988)]. 
plex mixture of proteins which, after precipitation in the absence of biotinylated probe, generates a weak background protein pattern (lane 2). When, as described previously (Sturm et al. 1987), reiterated and biotinylated copies of the wild-type SV40 site I sequence $(14 \times \mathrm{B} 17)$ are included in the precipitation assay, a single new band representing OBP100 appears (lane 3). A pair of point mutations $(d p m 8)$ within SV40 site I, which prevents complex formation (Sturm et al. 1987), also prevents precipitation of OBP100 without affecting the background pattern of precipitated proteins (lane 4). This result further emphasizes that although OBP100 can display remarkably flexible sequence recognition, this recognition is still sequence specific and can be affected by simple point mutations.

To assay the proteins that bind to the TAATGARAT motif in the heparin-agarose-purified HeLa cell fraction, we used ligated, double-stranded, synthetic oligonucleotides instead of restriction fragments. As expected, ligated synthetic oligonucleotides for an unrelated sequence (SV40 coreA, lane 5) did not precipitate OBP100, but wild-type SV40 site I oligonucleotides (lane 6) did precipitate OBP100. The background pattern of nonspecific proteins was very similar, but not identical, whether restriction fragments (lanes 3 and 4) or synthetic oligonucleotides (lanes 5-7) were used. The pattern of proteins after DNA affinity precipitation with the TAATGARAT motif containing oligonucleotide (lane 7) is indistinguishable from the pattern generated by the wild-type SV40 site I oligonucleotides (lane 6). Thus OBP100 is responsible for the TAATGARAT interactions, and in these experiments no ancillary proteins appear to be involved in OBP100 binding to the TAATGARAT motif. Together with the similar migration of the SV40 site I and TAATGARAT motif gel regardation complexes, this result suggests that OBP100 can bind independently of other factors to both of these two seemingly very different sequences.

\section{Discussion}

Extreme degeneracy in DNA sequence recognition by eukaryotic trans-acting factors has become evident in recent studies of promoter-binding proteins (Johnson et al. 1987; Pfeifer et al. 1987; Sturm et al. 1987; Costa et al. 1988; Michael et al. 1988; this paper). A system that has been well characterized genetically is the yeast HAPl activator interaction with a binding site in the upstream activator sequence UAS1 of the CYC1 gene and a binding site in the UAS of the CYC7 gene (Pfeifer et al. 1987). Although HAP1 binding to the CYC1 UAS1 and $C Y C 7$ UAS shares many general features (e.g., major and minor groove contacts), the sequences do not exhibit any obvious similarity (seven matches in a 23-bp region). Our previous (Sturm et al. 1987) and current studies show that OBP100, which binds paradoxically to an extremely well-conserved motif, also displays remarkably degenerate sequence recognition. Through these studies, a relatively large number of OBP100binding sites, both with and without perfect octamer core sequences, have been examined. Figure 7 shows an alignment of many of the binding sites described here in which either the similarity (Fig. 7A) or dissimilarity (Fig. $7 \mathrm{~B}$ ) between binding sites is emphasized.

In Figure 7, a 14-nucleotide-long sequence is shown for each binding site because this is the full size of the largest OBP100-binding site we have analyzed-the SV40 site II sequence (see Fig. 2C,D). To the right of each sequence comparison is shown the number of sequence matches within the 14-bp stretch between the two adjacent sequences. These numbers overemphasize the dissimilarity between sites that closely match the octamer consensus (i.e., SV40 site I, H2B, IgH, and U2) because these sites are not very sensitive to changes in the sequences flanking the octamer sequence (e.g., SV40 site I is only 11 bp long; see Fig. 2B). Nevertheless, all of the binding sites shown are identical to the two adjacent

A

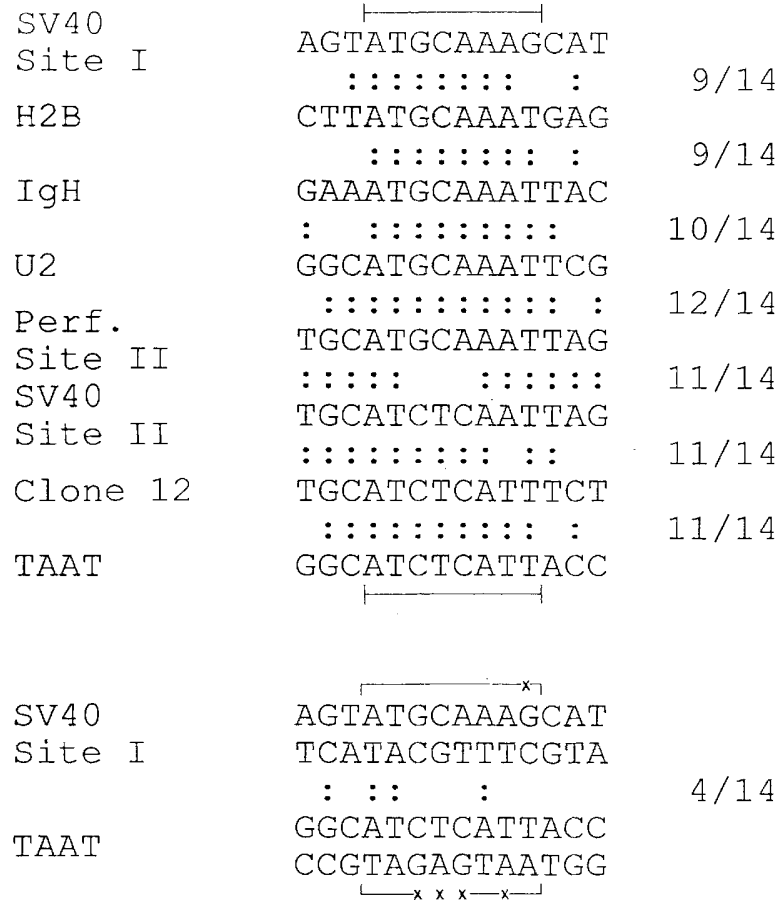

Figure 7. (A) Sequence comparison of different OBP100binding sites. Shown are six natural and two synthetic OBP100-binding sites as single-stranded sequence over a 14-bp region that was determined by the largest binding site (SV40 II). Except for clone 12 (a relatively weak binding site), data for the interaction of OBP100 with these sites in the form of gel retardation and chemical modification interference analyses are represented in this paper. The sequences are ordered to achieve the greatest degree of similarity between sites. The numbers to the right between sequences indicate the number of sequence matches (out of 14) between each pair. Base identity between sequences is shown by the colons. $(B)$ Direct comparison of SV40 site I and the TAATGARAT sequence. Double-stranded sequence of $14 \mathrm{bp}$ spanning each site is shown. The positions of the octamer-related sequences are outlined by brackets above (SV40 site I) or below (TAATGARAT) the sequence. $(\times)$ Mismatches with the consensus octamer motif. 
sequences shown at 9 or more positions out of 14 $(>60 \%)$ positions. In Figure 7A six of the eight sequences are natural OBP100-binding sites, whereas two of the sites (perfect octamer SV40 site II and clone 12) are mutants of SV40 site II sequences. By including these two latter binding sites, the transition between the perfect octamer motif in the U2 snRNA promoter-binding site and the TAATGARAT motif is shown with $>75 \%$ similarity at each position.

The provocative result of the sequence comparison shown in Figure 7A is that although a clear progression can be observed between each adjacent sequence, the two sites at the end of the progression, SV40 site I and the TAATGARAT motif, match at $<30 \%$ of the positions (Fig. 7B), which is little more than a random match. Thus, these two apparently unrelated sequences bind the same factor OBP100, and their relationship can be uncovered by the larger number of binding sites that have been analyzed (Fig. 7A). In contrast, in the studies of HAP1 (Pfeifer et al. 1987) and other degenerate sequence-binding proteins (Johnson et al. 1987; Costa et al. 1988, Michael et al. 1988), it has not been possible to establish the relationship between very different binding sites. The sequence comparison shown in Figure 7, together with the loss of requirement for flanking sequences when a degenerate octamer motif (site II) is converted to a perfect octamer motif, argues that OBP100 can bind to very dissimilar sequences because few, if any, residues are obligatory for binding. Instead, the sum of many independent contacts result in effective binding.

It is not possible from the experimental approach described here to determine whether the effects on OBP100 binding by sequence alterations or chemical modifications are due to changes in base contacts between OBP100 and the DNA-binding site or changes in DNA structure. For example, OBP100 is likely to bind to the octamer motif with the DNA in a particular conformation (e.g., a certain width of the minor groove, curvature of the DNA helix, etc.), and this conformation may be stabilized by flanking sequences. Thus, if putative base-specific contacts are debilitated by mutations within the core sequence, then the OBP100 interaction may be stabilized by those flanking sequences that favor the correct DNA conformation for OBP100 binding.

The influence of flanking sequences to compensate for deleterious mutations within a perfect octamer motif shows how difficult it is to draw conclusions from mutational analyses of a functional protein-binding site. For example, Staudt et al. (1986) performed an extensive mutational analysis of a consensus octamer/decamer motif (ATGCAAATNA) cloned into the pUC18 polylinker and showed that transversions in positions 1-7 all severely affected the interaction of the ubiquitous octamer-binding factor NF-A1, which probably represents OBP100, as well as the lymphoid-specific factor NF-A2. These results suggested that nearly every position of the highly conserved octamer motif was essential for interaction with the octamer-binding proteins. Partially, for this reason, we were surprised to find that OBP100 could bind to a degenerate octamer motif (Octa3) within the SV40 enhancer (Sturm et al. 1987). However, the experiments presented here show that the sequence context of a binding site is critical and a mutation that has a deleterious effect in one context may have little effect in a different context.

The context-dependent effect of mutations within a DNA-binding site may also explain the ability of mutations within the DNA-binding protein itself to have a differential effect on binding to one site versus another. For example, Pfeifer et al. (1987) have described a mutant HAP1 protein (HAP1-18) that affects binding to the CYC1 UAS1 but not the CYC7 UAS. Such an effect could be explained if the HAP1-18 mutation interferes with a binding site contact that is essential for $C Y C 1$ interaction but not CYC7. By analogy, a mutation in OBP100 that affects the ability to recognize residues flanking the octamer motif is likely to have a large effect on SV40 site II binding, where contacts with flanking residues are important, but not on binding to a perfect octamer motif, where flanking residue contacts are less important. These interpretations suggest that modifications of transcription factors may also have subtle effects on the patterns of sequence recognition.

The identification of many degenerate octamer motifs that can bind to ubiquitous OBP raises the question of why the octamer motif has been so well conserved in many upstream promoter and enhancer regions. The answer may lie in that the degenerate motifs are almost all exclusively of viral origin and that many of the degenerate motifs appear to bind OBP100 with a lower affinity than the perfect octamer motifs (see Fig. 3). Except for a few cases [e.g., the human Ul promoter (Mangin et al. 1986)], the octamer motif is highly conserved in cellular promoters, particularly the large number of immunoglobulin upstream promoter regions where the octamer motif was identified first (Falkner and Zachau 1984; Parslow et al. 1984). This strongly suggests that a good match to the octamer consensus is required for effective promoter activity. The preponderance of degenerate octamer motifs in DNA viruses such as the SV40 early promoter and HSV immediate early gene promoters may indicate a mechanism by which viruses can recruit host cellular factors for viral transcription. For example, these viruses may express factors that are able to alter the relative affinity of OBP100 for perfect and degenerate octamer motifs favoring the degenerate viral motifs. Such a mechanism would allow a virus to reprogram the DNA-binding specificity of cellular factors such that the cellular binding sites do not compete for the host transcriptional apparatus.

A good candidate for a factor that can reprogram the DNA-binding specificity of OBP100 is the HSV late protein VP16 (Vmw65). VP16 has been shown to activate the HSV immediate early region genes, in part, through the TAATGARAT motif but probably in conjunction with a cellular intermediate (see Triezenberg et al. 1988a). Recently, O'Hare and Goding (1988) have shown that VP16 expression can result in trans-activation of promoters containing octamer motifs and that octamer 
and TAATGARAT motifs can compete for the same cellular factor(s) in a HeLa cell nuclear extract. Our results on direct interaction of OBP100 with the TAATGARAT motif suggest that OBP100 itself may be the cellular mediator of VP16 trans-activation. The interaction of OBP100 with the TAATGARAT motif analyzed here, however, is weaker than the interaction with the perfect octamer motifs. Thus, OBP100 sequence recognition may be altered by interaction with VP16 to recognize the TAATGARAT motif more favorably. In the cases where the TAATGARAT motif is overlapped by an octamer motif, VP16 may shift the binding site preference from the octamer motif to the TAATGARAT motif or may facilitate dimerization of OBP100 at these sites.

\section{Methods}

With only a few modifications, the methods used in this paper for HeLa cell extract preparation, heparin-agarose chromatography, gel retardation and chemical modification interference assays, and sequence-specific DNA affinity-precipitation assays are described by Sturm et al. (1987).

\section{Origin and cloning of octamer and TAATGARAT probes}

The murine IgH enhancer, Ad2 ITR, human U2 snRNA distal element, and chicken histone $\mathrm{H} 2 \mathrm{~B}$ octamer motifs were obtained as restriction fragments from wild-type sequences or cloned synthetic oligonucleotides: The IgH enhancer probe was the HindIII-PstI fragment from $\mathrm{p} \beta \mathrm{IgH}^{+}$described previously (Sturm et al. 1987), 5' or $3^{\prime}$ end labeled at the HindIII site; the Ad2 ITR probe was a 72-bp EcoRI-SalI fragment derived from the left end of the Ad2 genome in the plasmid pLAS 108 (Tamanoi and Stillman 1983), 5' or $3^{\prime}$ end labeled at the EcoRI site; the U2 snRNA probe was an EcoRI-AvaI fragment from the clone NE (Ares et al. 1987), 3' end labeled at either the EcoRI or AvaI sites; and the H2B promoter fragment was an EcoRI-PstI fragment, either $5^{\prime}$ or $3^{\prime}$ end labeled at the EcoRI site, from a pUCl19 clone of the paired synthetic oligonucleotides GATCCTAGCCCCTCTATGCAAATGAGAAGCATTCCTTTCGAATT (top strand only) in the SmaI site.

The HSV ICP4 promoter fragment containing the -260 TAATGARAT motif and used for DEPC modification interference was prepared as an $S p h I-N c o I$ fragment from the plasmid pIE3CAT (DeLuca and Schaffer 1985), which was generously provided by Dr. N. DeLuca. For the competition assay and DNA affinity-precipitation assay, we used paired oligonucleotides that derived from the -265 to -245 region of the ICP4 promoter (numbering system from Mackem and Roizman 1982a) (GCGGTAATGAGATGCCATGCGGCTCGA and AGCCGCATGGCATCTCATTACCGCTCG; Xhol linker sequences are underlined) and that generated 3-bp 3' overhangs after annealing. For the competition assay, end-repaired annealed oligonucleotides were cloned as one copy into the SmaI site of pUC119. For DNA affinity precipitation the synthetic oligonucleotides themselves were concatenated by ligation (see below).

\section{Generation of wild-type and mutant SV4O OBP100-binding sites $I$ and $I I$}

Individual single-stranded synthetic oligonucleotides corresponding to SV40 binding sites I and II either were cloned directly, as described (Derbyshire et al. 1986), or used for site-directed in vitro mutagenesis of existing binding sites (Zoller and
Smith 1984; Kunkel 1985). Direct cloning was performed for the clones of the SV40 site I shown in Figure 2B (lanes 1 and 2) and the SV40 site II clones shown in Figure 2C. The SV40 site I clone in Figure 2B (lane 3) was generated by oligonucleotide-directed insertion of the $3^{\prime} \mathrm{A}$, whereas the clones containing a mutated SV40 site II in Figures 2D and 4A were generated by oligonucleotide-directed mutagenesis of the wild-type SV40 site II sequence shown in Figure 2C (lane 3). Direct cloning was performed into the plasmid $\mathrm{p}^{-} \mathrm{e}^{-}$, which contains the human $\beta$-globin gene (Ondek et al. 1987), with an upstream deletion from -37 to -127 of the $\beta$-globin promoter (T. Baumruker, unpubl.|, using single-stranded oligonucleotides with PstI- and XbaI-compatible termini. A 100 -fold molar excess of singlestranded phosphorylated oligonucleotide was ligated overnight to PstI-digested and dephosphorylated $\mathrm{p} \beta \mathrm{e}^{-} \Delta$ vector. Excess oligonucleotide was removed by two sequential ethanol precipitations in the presence of $2 \mathrm{M}$ ammonium acetate, and the plasmid redigested with $\mathrm{XbaI}$. Ligation was then performed either after 50 -fold dilution of the DNA or after purification of the resulting large vector fragment on a low-melting-point agarose gel. After ligation, the DNAs were transfected into MV1 193 cells. Loss of the 2.2 -kb $\beta$-globin fragment was used to screen rapidly for successful cloning of oligonucleotides. Point mutations were introduced using suitable single-stranded parental plasmid DNAs prepared from the ung ${ }^{-} d u t^{-} E$. coli strain BW313 (Kunkel 1985) as templates for oligonucleotidedirected mutagenesis (Zoller and Smith 1984). The nucleotide sequence of all probes was confirmed by complete DNA sequencing using the dideoxy method (Sanger et al. 1977).

\section{Preparation of probes for gel retardation and chemical modification interference assays}

Fragments used for chemical modification interference were either 3' end labeled with the large fragment of DNA polymerase I or $5^{\prime}$ end labeled with T4 polynucleotide kinase, modified with DEPC or DMS, and subsequently purified by preparative polyacrylamide gel electrophoresis, as described previously (Sturm et al. 1987). For gel retardation assays with wild-type and mutant SV40 binding sites I and II or the TAATGARAT motif, we used continuously labeled probes generated by de novo synthesis of double-stranded DNA from a single-stranded template. This labeling procedure ensured that all probes were labeled reproducibly to the same specific activity. To generate these continuously labeled probes, the 'universal' sequencing primer was annealed to single-stranded pUC119 DNA, generated by superinfection with the helper phage M13K07 (Vieira and Messing 1987), and extended by incubation with the large fragment of DNA polymerase I and nucleotide triphosphates in which one nucleotide was ${ }^{32} \mathrm{P}$ labeled. After $10 \mathrm{~min}$ incubation at ambient temperature, the reaction was terminated by addition of ammonium acetate to a final concentration of $2 \mathrm{M}$ and subsequent phenol/chloroform $(1: 1)$ extraction and ethanol precipitation. After digestion with EcoRI and HindIII, the resulting probes were purified by preparative polyacrylamide gel electrophoresis and elution into $10 \mathrm{~mm}$ Tris- $\mathrm{HCl}(\mathrm{pH} 8.0), 1 \mathrm{~mm}$ EDTA at $37^{\circ} \mathrm{C}$. The resulting eluate was collected, and the DNA concentration adjusted to $10,000 \mathrm{cpm}$ (Cerenkov) $/ \mu 1$ for direct use in the gel retardation.

\section{OBP100 purification, gel retardation, and chemical modification interference}

Except for the highly purified OBP100 used in Figure 1A, which was the same purified OBP100 protein described previously (Sturm et al. 1987), the source of OBP activity was the $0.1-0.2$ 
M KCl heparin-agarose column fraction from nuclear HeLa cell extracts prepared as described previously (Sturm et al. 1987), but the Bio-Gel P-10 column chromatography was replaced by dialysis in some cases. We modified the binding buffer for the preparative gel retardations of chemically modified fragments by removal of $\mathrm{MgCl}_{2}$ and addition of $10 \mathrm{~mm}$ EDTA. This modification inhibited nucleases in the extract but did not affect the gel retardation patterns themselves. Otherwise, the procedures were as described previously. The exact DEPC modification responsible for the interference patterns is unknown but probably reflects carbethoxylation at the N7 position. This is because even though DEPC can modify other positions on adenines (i.e., $\mathrm{N} 1$ and N3) these are probably not sensitive to the piperidine cleavage step that displays sites of modification. Modification at the N7 position is consistent with the patterns of DEPC reactivity to left-handed Z DNA (see Herr 1985).

\section{DNA affinity precipitation}

The microscale biotin/avidin DNA affinity-precipitation assay was carried out as described (Franza et al. 1987; Sturm et al. 1987), either using biotinylated $14 \times B 17$ (Ondek et al. 1987) or $6 \times \mathrm{XB} 17 \mathrm{dpm} 8$ (W. Herr, unpubl.) restriction fragments, or oligonucleotides containing the SV40 OBP100 site I (sphII/MsphI. Ondek et al. 1988), the SV40 coreA motif (coreA/coreA; Ondek et al. 1988), or the TAATGARAT motif separated by XhoI recognition sites were kinased, annealed, and ligated. The extent of oligonucleotide ligation was determined by gel electrophoresis (average, more than four), and the ligated products were biotinylated, after phenol/chloroform extraction and ethanol precipitation. Approximately $0.4 \mu \mathrm{g}$ of biotinylated DNA, either as restriction fragments or ligated oligonucleotides, was used to directly identify OBP 100 protein in $350 \mu$ l of heparinagarose-fractionated HeLa cell extract (Sturm et al. 1987). Proteins precipitated after attachment of the biotinylated DNAs to streptavidin-agarose beads and several washes were resolved by SDS-polyacrylamide gel electrophoresis and visualized by silver staining.

\section{Acknowledgments}

We thank J. Clarke for aiding in heparin-agarose purification of OBP100 and establishment of the DNA affinity-precipitation technique; N. DeLuca for kindly providing the plasmid pIECAT; M. Zoller for synthetic oligonucleotides; R. Duffy and $M$. Goodwin for help in preparing the manuscript, D. Greene, J. Duffy, and M. Ockler for artwork; and B.R. Franza, M. Gilman, N. Hernandez, and B. Stillman for critical readings of the manuscript. T.B. is a recipient of an EMBO long-term fellowship; R.S. is a recipient of a Cancer Research Institute postdoctoral fellowship, New York; W.H. is a Rita Allen Foundation Scholar. This work was supported by U.S. Public Health Services grant CA-13106 from the National Cancer Institute.

\section{References}

Ares, M., Jr., M. Mangin, and A.M. Weiner. 1985. Orientationdependent transcriptional activator upstream of a human U2 snRNA gene. Mol. Cell. Biol. 5: 1560-1570.

Ares, M. Jr., J.-S. Chung, L. Giglio, and A.M. Weiner. 1987. Distinct factors with Spl and NF-A specificities bind to adjacent functional elements of the human U2 snRNA gene enhancer. Genes Dev. 1: 808-817.

Benoist, C., K. O'Hare, R. Breathnach, and P. Chambon. 1980. The ovalbumin gene-sequence of putative control regions. Nucleic Acids Res. 8: 127-142.
Campbell, M.E.M., J.W. Palfreyman, and C.M. Preston. 1984. Purification of herpes simplex virus DNA sequences which encode a trans-acting polypeptide responsible for stimulation of immediate early transcription. $J$. Mol. Biol. 180: 119.

Costa, R.H., D.R. Grayson, K.G. Xanthopoulos, and J.E. Darnell, Jr. 1988. A liver-specific DNA-binding protein recognizes multiple nucleotide sites in regulatory regions of transthyretin, $\alpha_{1}$-antitrypsin, albumin, and simian virus 40 genes. Proc. Natl. Acad. Sci. 85: 3840-3844.

Davidson, I., C. Fromental, P. Augereau, A. Wildeman, M. Zenke, and P. Chambon. 1986. Cell-type specific protein binding to the enhancer of simian virus 40 in nuclear extracts. Nature 323: 544-548.

DeLuca, N.A. and P.A. Schaffer. 1985. Activation of immediate-early, early, and late promoters by temperature-sensitive and wild-type forms of herpes simplex virus type 1 protein ICP4. Mol. Cell. Biol. 5: 1997-2008.

Derbyshire, K.M., J.J. Salvo, and N.D.F. Grindley. 1986. A simple and efficient procedure for saturation mutagenesis using mixed oligodeoxynucleotides. Gene 46: 145-152.

Dynan, W.S. and R. Tjian. 1983. The promoter-specific transcription factor $\mathrm{Spl}$ binds to upstream sequences in the SV40 early promoter. Cell 35: 79-87.

Efstratiadis, A., J.W. Posakony, T. Maniatis, R.M. Lawn, C. O'Connell, R.A. Spritz, J.K. DeRiel, B.G. Forget, S.M. Weissman, J.L. Slightom, A.E. Blechl, O. Smithies, F.E. Barale, C.C. Shoulders, and N.J. Proudfoot. 1980. The structure and evolution of the human $\beta$-globin gene family. Cell 21: 653-668.

Falkner, F.G. and H.G. Zachau. 1984. Correct transcription of an immunoglobulin $\kappa$ gene requires an upstream fragment containing conserved sequence elements. Nature 310: 7174.

Falkner, F.G., R. Mocikat, and H.G. Zachau. 1986. Sequences closely related to an immunoglobulin gene promoter/enhancer element occur also upstream of other eukaryotic and of prokaryotic genes. Nucleic Acids Res. 14: 8819-8827.

Fletcher, C., N. Heintz, and R.G. Roeder. 1987. Purification and characterization of OTF-1, a transcription factor regulating cell cycle expression of a human histone $\mathrm{H} 2 \mathrm{~b}$ gene. Cell 51: 773-781.

Franza, B.R., Jr., S.F. Josephs, M.Z. Gilman, W. Ryan, and B. Clarkson. 1987. Characterization of cellular proteins recognizing the HIV enhancer using a microscale DNA-affinity precipitation assay. Nature 330: 391-395.

Gerster, T. and R.G. Roeder. 1988. A herpesvirus trans-activating protein interacts with transcription factor OTF-1 and other cellular proteins. Proc. Natl. Acad. Sci. 85: 63476351.

Gerster, T., P. Matthias, M. Thali, J. Jiricny, and W. Schaffner. 1987. Cell type-specificity elements of the immunoglobulin heavy chain gene enhancer. EMBO J. 6: 1323-1330.

Harvey, R.P., A.J. Robins, and J.R.E. Wells. 1982. Independently evolving chicken histone $\mathrm{H} 2 \mathrm{~B}$ genes: identification of a ubiquitous H2B-specific 5' element. Nucleic Acids Res. 10: $7851-7863$.

Herr, W. 1985. Diethyl pyrocarbonate: A chemical probe for secondary structure in negatively supercoiled DNA. Proc. Natl. Acad. Sci. 82: 8009-8013.

Herr, W. and J. Clarke. 1986. The SV40 enhancer is composed of multiple functional elements that can compensate for one another. Cell 45: 461-470.

Johnson, P.F., W.H. Landschultz, B.J. Graves, and S.L. McKnight. 1987. Identification of a rat liver nuclear protein that binds to the enhancer core element of three animal vi- 
ruses. Genes Dev. 1: 133-146.

Kristie, T.M. and B. Roizman. 1984. Separation of sequences defining the basal expression from those conferring $\alpha$ gene recognition within the regulatory domains of Herpes simplex virus $1 \alpha$ genes. Proc. Natl. Acad. Sci. 81: 4065-4069.

- 1987. Host cell proteins bind to the cis-acting site required for virion-mediated induction of herpes simplex virus $1 \alpha$ genes. Proc. Natl. Acad. Sci. 84: 71-75.

Kunkel, T.A. 1985. Rapid and efficient site-specific mutagenesis without phenotypic selection. Proc. Natl. Acad. Sci. 82: $488-492$.

LaBella, F., H.L. Sive, R.G. Roeder, and N. Heintz. 1988. Cellcycle regulation of a human histone $\mathrm{H} 2 \mathrm{~b}$ gene is mediated by the $\mathrm{H} 2 \mathrm{~b}$ subtype-specific consensus element. Genes Dev. 2: $32-39$.

Landolfi, N.F., J.D. Capra, and P.W. Tucker. 1986. Interaction of cell-type-specific nuclear proteins with immunoglobulin $\mathrm{V}_{\mathbf{H}}$ promoter region sequences. Nature 323: 548-551.

Mackem, S. and B. Roizman. 1982a. Differentiation between $\alpha$ promoter and regulator regions of herpes simplex virus 1 : The functional domains and sequence of a movable $\alpha$ regulator. Proc. Natl. Acad. Sci. 79: 4917-4921.

- 1982b. Structural features of the herpes simplex virus $\alpha$ gene 4,0 , and 27 promoter-regulatory sequences which confer $\alpha$ regulation on chimeric thymidine kinase genes. $J$. Virol. 44: 939-949.

Mangin, M., M. Ares, Jr., and A.M. Wiener. 1986. Human U2 small nuclear RNA genes contain an upstream enhancer. EMBO J. 5: 987-995.

Marsden, H.S., M.E.M. Cambpell, L. Haarr, M.C. Frame, D.S. Parris, M. Murphy, R.G. Hope, M.T. Muller, and C.M. Preston. 1987. The 65,000-Mr DNA binding and virion trans-inducing proteins of Herpes simplex virus type 1. I. Virol. 61: 2428-2437.

Mattaj, I.W., S. Lienhard, J. Jiricny, and E.M. De Robertis. 1985. An enhancer-like sequence within the Xenopus U2 gene promoter facilitates the formation of stable transcription complexes. Nature 316: 163-167.

McKnight, J.L.C., T.M. Kristie, and B. Roizman. 1987. Binding of the virion protein mediating $\alpha$ gene induction in herpes simplex virus 1 -infected cells to its cis site requires cellular proteins. Proc. Natl. Acad. Sci. 84: 7061-7065.

Michael, N., D. Spector, P. Mavromara-Nazos, T.M. Kristie, and B. Roizman. 1988. The DNA-binding properties of the major regulatory protein $\alpha 4$ of herpes simplex viruses. Science 239: 1531-1534.

O'Hare, P. and C.R. Goding. 1988. Herpes simplex virus regulatory elements and the immunoglobulin octamer domain bind a common factor and are both targets for virion transactivation. Cell 52: 435-445.

Ondek, B., L. Gloss, and W. Herr. 1988. The SV40 enhancer contains two distinct levels of organization. Nature 333: $40-45$.

Ondek, B., A. Shepard, and W. Herr. 1987. Discrete elements within the SV40 enhancer region display different cell specific enhancer activities. EMBO /. 6: 1017-1025.

O'Neill, E.A. and T.J. Kelly. 1988. Purification and characterization of nuclear factor III (origin recognition protein C) a sequence-specific DNA binding protein required for efficient initiation of adenovirus DNA replication. $J$. Biol. Chem. 263: 931-937.

Parslow, T.G., D.L. Blair, W.J. Murphy, and D.K. Granner. 1984. Structure of the $5^{\prime}$ ends of immunoglobulin genes: A novel conserved sequence. Proc. Natl. Acad. Sci. 81: 2650-2654.

Pfeifer, K., T. Prezant, and L. Guarente. 1987. Yeast HAP1 activator binds to two upstream activation sites of different sequence. Cell 49: 19-27.
Preston, C.M, M.G. Cordingley, and N.D. Stow. 1984. Analysis of DNA sequences which regulate the transcription of a Herpex simplex virus immediate early gene. I. Virol. 50: $708-716$.

Preston, C.M., M.C. Frame, and M.E.M. Campbell. 1988. A complex formed between cell components and an HSV structural polypeptide binds to a viral immediate early gene regulatory DNA sequence. Cell 52: 425-434.

Pruijn, G.J.M., W. van Driel, and P.C. van der Vliet. 1986. Nuclear factor III, a novel sequence-specific DNA-binding protein from HeLa cells stimulating adenovirus DNA replication. Nature 322: 656-659.

Pruijn, G.J.M., W. van Driel, R.T. van Miltenburg, and P.C. van der Vliet. 1987. Promoter and enhancer elements containing a conserved sequence motif are recognized by nuclear factor III, a protein stimulating adenovirus DNA replication. EMBO 1. 6: 3771-3778.

Rosales, R., M. Vigneron, M. Macchi, I. Davidson, J.H. Xiao, and P. Chambon. 1987. In vitro binding of cell-specific and ubiquitous nuclear proteins to the octamer motif of the SV40 enhancer and related motifs present in other promoters and enhancers. EMBO I. 6: 3015-3025.

Rosenfeld, P.J., E.A. O'Neill, R.J. Wides, and T.J. Kelly. 1987. Sequence-specific interactions between cellular DNAbinding proteins and the adenovirus origin of DNA replication. Mol. Cell. Biol. 7: 875-886.

Sanger, F., S. Nicklen, and A.R. Coulson. 1977. DNA sequencing with chain-terminating inhibitors. Proc. Natl. Acad. Sci. 74: 5463-5467.

Scheidereit, C., A. Heguy, and R.G. Roeder. 1987. Identification and purification of a human lymphoid-specific octamer binding protein (OTF-2) that activates transcription of an immunoglobulin promoter in vitro. Cell 51: 783-793.

Singh, H., R. Sen, D. Baltimore, and P.A. Sharp. 1986. A nuclear factor that binds to a conserved sequence motif in transcriptional control elements of immunoglobulin genes. Nature 319: $154-158$.

Staudt, L.M., H. Singh, R. Sen, T. Wirth, P.A. Sharp, and D. Baltimore. 1986. A lymphoid-specific protein binding to the octamer motif of immunoglobulin genes. Nature 323: 640643.

Sturm, R., T. Baumruker, B.R. Franza, Jr., and W. Herr. 1987. A $100-\mathrm{kD}$ HeLa cell octamer binding protein (OBP100) interacts differently with two separate octamer-related sequences within the SV40 enhancer. Genes Dev. 1: 11471160 .

Tamanoi, F. and B.W. Stillman. 1983. Initiation of adenovirus DNA replication in vitro requires a specific DNA sequence. Proc. Nat1. Acad. Sci. 80: 6446-6450.

Triezenberg, S.J., R.C. Kingsbury, and S.L. McKnight. 1988a. Functional dissection of VP16, the transactivator of herpes simplex virus immediate early gene expression. Genes Dev. 2: 718-729.

Triezenberg, S.J., K.L. LaMarco, and S.L. McKnight. 1988b. Evidence of DNA: protein interactions that mediate HSV-1 immediate early gene activation by VP16. Genes Dev. 2: 730742.

Vieira, J. and J. Messing. 1987. Production of single-stranded plasmid DNA. Methods Enzymol. 153: 3-11.

Wirth, T., L. Staudt, and D. Baltimore. 1987. An octamer oligonucleotide upstream of a TATA motif is sufficient for lymphoid-specific promoter activity. Nature 329: 174-178.

Zoller, M.J. and M. Smith. 1984. Oligonucleotide-directed mutagenesis: A simple method using two oligonucleotide primers and a single-stranded DNA template. DNA 3: 479488 . 


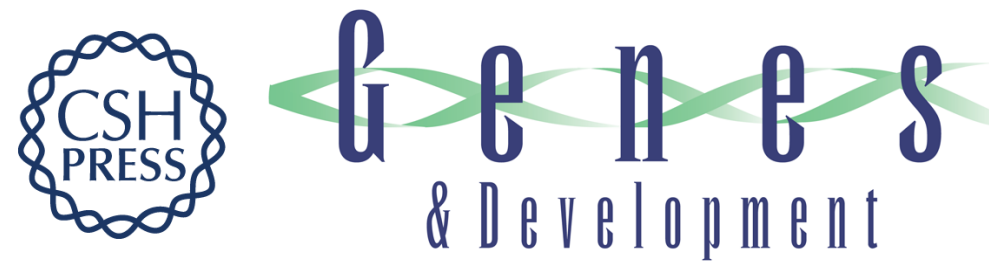

\section{OBP100 binds remarkably degenerate octamer motifs through specific interactions with flanking sequences.}

T Baumruker, R Sturm and W Herr

Genes Dev. 1988, 2:

Access the most recent version at doi:10.1101/gad.2.11.1400

References This article cites 55 articles, 25 of which can be accessed free at:

http://genesdev.cshlp.org/content/2/11/1400.full.html\#ref-list-1

License

Email Alerting

Service

Receive free email alerts when new articles cite this article - sign up in the box at the top right corner of the article or click here.

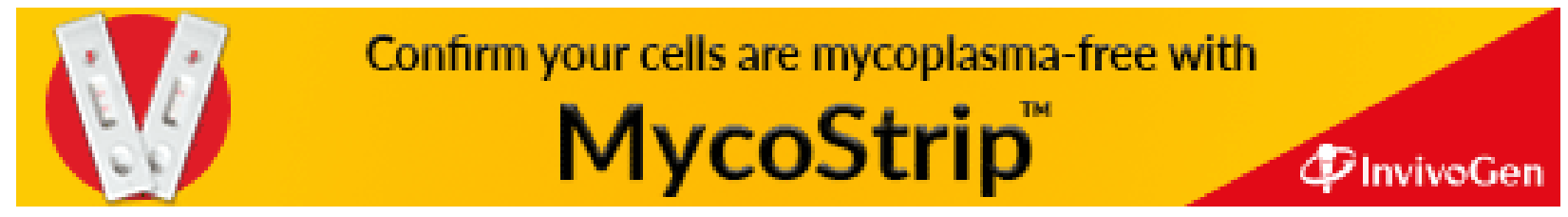

